\title{
Fortificaciones medievales en el espacio portu- gués: propuesta de una síntesis global para su evolución
}

Joaquim Manuel Rodrigues dos Santos

CIAUD (Faculdade de Arquitectura - Universidade Técnica de Lisboa)

Artículo recibido: 23-2-2012 / Aceptado: 8-6-2012

Resumen: Se pretende efectuar un bosquejo conciso de la evolución de las fortificaciones medievales en el espacio portugués con base en bibliografía castellológica de referencia, proponiéndose una estructura que permite conjugar sintéticamente la evolución de las fortificaciones a partir de varios puntos de vista dispersos por diversas investigaciones, encontrando una línea conductora global a nivel historiográfico que permite contextualizar de modo más coherente esa evolución.

Palabras clave: Portugal; Fortificaciones Medievales; Castellología

ABstract: This text intends to compose a concise synthesis of the evolution of medieval fortifications in the Portuguese territory, supported by essential bibliography. It is proposed here a structure combining the development of fortifications from several viewpoints which were presented in numerous investigations; this way, is possible to find a global line in the historiographical context which allows a more coherent contextualization of that evolution.

Keywords: Portugal; Medieval Fortifications; Castelology

\section{PREÁMBULO}

Como parte de la disertación doctoral cuyo objetivo principal buscó componer el recorrido de las fortificaciones medievales portuguesas como bienes patrimoniales ${ }^{1}$, se

${ }^{1}$ Anamnesis del Castillo como Bien Patrimonial: Construcción de la Imagen, Forma y (Re)Funcionalización en la Rehabilitación de Fortificaciones Medievales en Portugal, disertación doctoral en Arquitectura realizada en la Universidad de Alcalá (2012), bajo dirección de Javier Rivera Blanco y de Maria João Neto. consideró necesario conocer más profundamente el propio objeto de estudio: las varias fortificaciones medievales portuguesas en sus diversas vertientes. Por lo que fue analizada la castellología producida a lo largo del tiempo en Portugal, permitiendo una amplia contextualización de la evolución de las fortificaciones medievales en el espacio portugués.

Existen numerosas obras de investigación sobre las fortificaciones portuguesas 
dedicadas a determinadas épocas, espacios, fortificaciones, orígenes u otros temas delimitadores; y existen también algunas síntesis que analizan el recorrido evolutivo general de las fortificaciones en Portugal. Recurriendo al conocimiento adquirido en el análisis a la castellología portuguesa, se pretende efectuar un bosquejo conciso de la evolución de las fortificaciones medievales en el espacio portugués con base en bibliografía castellológica de referencia. Como contribución personal se propone la estructura que permite conjugar sintéticamente la evolución de las fortificaciones a partir de varios puntos de vista dispersos por diversas investigaciones, como por ejemplo relacionando la evolución de los castillos de origen musulmana conjuntamente con los cristianos, refiriendo en el estudio los palacios acastillados, templos fortificados y otros edificios defensivos, y encontrando una línea conductora global a nivel historiográfico que permite contextualizar de modo más coherente esa evolución.

\section{EVOLUCIÓN DE LAS FORTIFICACIONES MEDIEVALES EN EL ESPACIO PORTU- GUÉS}

Conforme afirma Mário Varela Gomes, el instinto de supervivencia de las poblaciones ha estado intrínsecamente relacionado con la necesidad de construir sistemas defensivos ${ }^{2}$, y en el territorio que es hoy Portugal las primeras estructuras fortificadas surgieron aún en el tercer milenio antes de Cristo. Inicialmente levantados en la parte meridional ${ }^{3}$ - debido probable-

${ }^{2}$ M. V. GOMES, "Das Origens à Romanização” in R. MOREIRA (dir.), História das Fortificações Portuguesas no Mundo, Lisboa, 1989, p. 9.

${ }^{3}$ Sobre las fortificaciones prerromanas, romanas e islámicas en el occidente peninsular, ver: R. V. GOMES, Silves (Xelb) - Uma Cidade do Gharb Al-Andalus: Arqueologia e História (Séculos VIII-XIII), Disertación de Doctorado (Universidad Nova de Lisboa), 1999; C. TORRES, S. MACIAS, O Legado Islâmico em Portugal, Lisboa, 1998; H. G. CATARINO, O Algarve Oriental Durante a Ocupação Islâmica: Povoamento Rural e Recintos Fortificados, Disertación de Doctorado (Universidad de Coimbra), 1997; mente a influencias mediterráneas motivadas por contactos entre pueblos nativos y fenicios, púnicos y griegos -, los poblados fortificados ${ }^{4}$ empezaron a surgir también en el territorio septentrional en el inicio del primer milenio antes de Cristo, constatándose su decadencia en la segunda mitad del siglo I de nuestra era ante la romanización. A pesar de la existencia de fortificaciones de anterior iniciativa romana ${ }^{5}$, sólo en la fase final del período imperial (finales del siglo III y siglo IV) se empezaron a

B. P. MALDONADO, Ciudades y Fortalezas Lusomusulmanas: Crónicas de Viajes por el Sur de Portugal, Madrid, 1993; M. V. GOMES, Op. cit. nota 2, pp. 9-26; R. V. GOMES, "A Arquitectura Militar Muçulmana” in R. MOREIRA (dir.), História das Fortificações Portuguesas no Mundo, Lisboa, 1989, pp. 27-37.

${ }^{4}$ Los primeros poblados fortificados se situaban generalmente en locales con buenas condiciones naturales para la defensa; existían sistemas de murallas sencillas o concéntricas de piedra o, en menor número, de tierra; las murallas presentaban frecuentemente planta curvilínea adaptada al terreno, surgiendo a veces reforzadas por fosos, bastiones y torres semicirculares y, en algunos casos, con puertas dobles o entradas en recodo. Son ejemplos el poblado fortificado de Zambujal (Torres Vedras), el castro de Terroso (Póvoa de Varzim), o la citania de Briteiros (Guimarães) (M. V. GOMES, Op. cit. nota 2, pp. 12-20).

${ }^{5}$ Durante las campañas de pacificación posteriores a la Segunda Guerra Púnica (218 a.C. a 201 a.C.) y conquista de la Península Ibérica, se construyeron campamentos fortificados romanos que generalmente presentaban fosos, taludes de tierra prensada y empalizadas con formas regulares. Algunos, tornados permanentes, ocasionaron ciudades como Pax Iulia (Beja) y Scallabis Praesidium Iullium (Santarém). Estas, junto con poblados preexistentes reformados por los romanos - sobre todo las oppida, cuyos nombres poseían el sufijo céltico briga (local fortificado) como Conímbriga (Condeixaa-Velha), Miróbriga (Santiago do Cacém), Caetóbriga (Setúbal) o Lacóbriga (Lagos) -, originaron la urbanización del territorio. Según Mário Varela Gomes las murallas pétreas de las ciudades romanizadas, además del carácter defensivo, constituían un símbolo honorífico del poder municipal local; la defensa territorial se complementaba con campamentos militares y castella (edificaciones rurales fortificadas de piedra y con planta regular) edificadas a partir del siglo I antes de Cristo, probablemente por emeriti (soldados romanos veteranos que se tornaron colonizadores), como el castella de Lousa (Mourão) o el castella de Manuel Galo (Mértola) (M. V. GOMES, Op. cit. nota 2, pp. 23-26). 
fortificar las principales ciudades ibéricas debido al clima de inseguridad provocado por luchas internas y por las incursiones de suevos, alanos, vándalos y visigodos, que culminaron con el fin del poder imperial en Península Ibérica en 411. Como resultado se reconstruyeron o reformularon cinturas amuralladas en las ciudades ibéricas ${ }^{6}$ como parte de un (pretendido) sistema defensivo territorial. Las murallas, a menudo construidas apresuradamente y con escasez de medios, presentaban torreones adosados de planta cuadrada o circular reforzándolas espaciadamente y defendiendo las puertas. A veces quedaban fuera del nuevo recinto amurallado importantes equipamientos $\mathrm{y}$ áreas urbanas.

La llegada al poder de los germánicos no trajo innovaciones a la arquitectura defensiva, sino que se asistió al reaprovechamiento generalizado de las fortificaciones romanas - sobre todo cercas urbanas amuralladas, que los visigodos frecuentemente revocaban con morteros de cal - y a la continuación de la tecnología castrense tardorromana (e incluso bizantina durante la época visigótica). La inestabilidad política vivida en las ciudades motivó a numerosos aristócratas y habitantes a apartarse de estas, propiciando una ruralización de la sociedad germanizada. Mientras algunas ciudades más poderosas se densificaron, otras sufrieron abandonos parciales $\mathrm{y}$, en algunos casos, fueron arrasadas y reconstruidas - no siempre coincidiendo entre $\mathrm{si}^{7}$.

${ }^{6}$ Por ejemplo Aeminium (Coimbra), Conímbriga (Condeixa-a-Velha), Civitas Igaeditanorum (Idanha-a-Velha), Olisippo Felicitas Iulia (Lisboa), Ebora Liberalitas Iulia (Évora), Myrtilis Iulia (Mértola) y Ossonoba (Faro).

${ }^{7}$ Walter Rossa menciona el caso de Bracara (Braga), convertida en capital del reino suevo que abarcaba sensiblemente la antigua provincia romana de Gallaecia. El núcleo cristiano quedaba situado alrededor de la nueva catedral y fuera de las murallas romanas, motivando la constitución de un nuevo centro urbano y una nueva muralla siguiendo un trazado distinto de la anterior (W. ROSSA, A Urbe e o Traço: Uma Década de Estudos Sobre o Urbanismo Português, Coimbra, 2002, p. 207).
En el año 711, aprovechando las luchas entre facciones visigodas, se dio la ocupación musulmana (en muchos casos consentida) de la Península Ibérica, completada en menos de una década. Menos de diez años después existió la reacción cristiana: en el 718, aprovechando disensiones entre árabes y beréberes, se inició la Reconquista Cristiana con la victoria en la batalla de Covadonga, que posibilitó la formación del reino cristiano de Asturias. En adelante y hasta el término de la reconquista del territorio portugués con la toma de Silves en 1249, la evaluación castellológica tiene que efectuarse de manera simultánea según los puntos de vista cristiano y musulmán, donde a cada avance tecnológico de uno replica el otro casi inmediatamente.

La estrategia de ocupación del Gharb al-Ândalus (suroeste de la Península Ibérica) por los musulmanes se basaba en la institución de compromisos con las poblaciones nativas hispanorromanas, lo que contribuyó a una relativa autonomía de esta región y, en la parte más septentrional, a un proceso de islamización más lento. Inicialmente los musulmanes se limitaron a cambiar el destinatario de los tributos y la cúpula del poder instituido, imponiendo a cada ciudad un $q \bar{a}^{\prime} d \bar{\imath}$ (juez administrador) y su séquito de dignatarios administrativos y militares. Para facilitar la administración del territorio peninsular, poco después de la ocupación se lo dividió en kūrah, circunscripciones militares entregadas a un jund (guarnición militar). Al recibir una red urbana relativamente consolidada, los musulmanes se establecieron en las ciudades existentes, implantando en sus puntos más altos y estratégicamente defendibles - a menudo sobreponiéndose al forum romano - la qas'bah (alcazaba), ciudadela que albergaba el centro del poder administrativo y religio$\mathrm{so}^{8}$. Siendo la nueva elite minoritaria étnica y religiosamente, la ciudadela era fortificada y aislada del resto de la urbe mediante complejos sistemas defensivos y espacios

${ }^{8}$ C. TORRES, S. MACIAS, Op. cit. nota 3, pp. 20-29. 
vedados a la edificación; tal contribuyó a marcar decisivamente el perfil ciudadano hispanomusulmán. Dentro de la qas'bah se localizaban el qas'r (alcázar, un palacio fortificado) y la másgid (mezquita), mientras que la restante urbe amurallada se designaba como madinah (medina, la ciudad amurallada).

La estrategia defensiva musulmana del período omeya (entre 711 y 1031) integraba un sistema centralizador defensivo contra cristianos, vikingos y fatimíes, donde las ciudades amuralladas se complementaban con una red de fortificaciones en las zonas fronterizas dispuestas con distancias más o menos regulares. La red estaba constituida por elementos fortificados como el hîşn (fortificación análoga a los castillos), el burdj (torre defensiva y de vigilancia a veces rodeada por murallas), el qal'a (pequeño poblado amurallado), el ribāt (rábida, templo fortificado musulmán que albergaba los faqìh, monjes guerreros), y el at-talay (torres atalayas para vigilancia) $)^{9}$. Sin embargo esta red no se aplicó desde el principio, sino se fue modelando a lo largo del tiempo en consonancia con las vicisitudes ocurridas.

Estas primeras fortificaciones musulmanas en el Gharb al-Ândalus aprovecharon inicialmente las anteriores fortificaciones existentes, continuando también siguiendo modelos tardorromanos y bizantinos del norte de África y Próximo Oriente ${ }^{10}$, con torreones semicilíndricos incorporados en los ángulos de las murallas de sillería,

9 Diversas ciudades poseyeron qas'bah, qas'r y madinah, como Ushbuna (Lisboa), Shantariyn (Santarém), Šanat Māria al-Hāarun (Faro), al-Qasr-al-Baja (Alcácer do Sal), Qulumriyya (Coimbra), Martulah (Mértola) y Shilb (Silves). La rábida de al-Rayhâna (Arrifana) es el ejemplo mejor estudiado de rábidas presentes en Portugal. En cuanto a casos de hîşn, existen varios documentados, como por ejemplo al-Jazirah (Aljezur), Massâna (Messines) o Marjiq (Monchique).

${ }^{10}$ De hecho los castellae (estructuras eminentemente militares de carácter defensivo que albergaban guarniciones de soldados) existían ya en la época imperial romana distribuidos a lo largo de limes fronterizos del imperio. puertas de acceso frontal flanqueadas por torres y, en los recintos fortificados de raíz, con la utilización de plantas geométricas cuadrangulares o rectangulares con patios interiores donde se encontraban la cisterna y el acuartelamiento ${ }^{11}$. Es muy probable que los primeros castillos (estructuras defensivas destinadas a albergar no un poblado sino una guarnición militar) edificados en el actual territorio portugués fueron musulmanes: el hîşn emiral omeya edificado a partir de mediados del siglo IX ${ }^{12}$. Siendo minoritarios entre una populación predominantemente cristiana, cercar las poblaciones de murallas no era una solución completamente eficaz para los musulmanes, puesto que se corría el riesgo de que posibles enemigos (o sus partidarios cristianos) pudieran quedarse también dentro del recinto amurallado - de ahí la existencia de qas'bah en las ciudades. Frente a poblaciones dispersas ruralizadas y eminentemente cristianas, era más eficaz la edificación de fortificaciones castrenses con objetivos dominadores sobre el territorio.

La dispersión y ruralización de las poblaciones era más acentuada en las partes septentrionales del territorio ibérico las menos islamizadas -, condiciones que propiciaron una relativa autonomía ${ }^{13}$. Ceñi-

\footnotetext{
${ }^{11}$ R. V. GOMES, Op. cit., nota 3, p. 28.

${ }^{12}$ Antes de la ocupación musulmana la defensa con-
} sistía en la fortificación de poblados con cercas amuralladas y, en algunos casos, recurriendo a la fortificación de residencias rurales, templos o torres. Las estructuras destinadas a guarniciones militares eran básicamente campamentos militares romanos puntuales que no pueden ser considerados castillos

${ }^{13}$ Las "tierras de nadie" situadas entre el reino asturiano y los territorios musulmanes (entre el río Duero y la cordillera cantábrica) no estaban desertificados, sino fuera del control musulmán o cristiano. Según Carlos Riley éstas eran zonas fronterizas periféricas entre las dos formaciones político-religiosas donde la autonomía de sus poblaciones propiciaba una fidelidad variable entre las dos partes. En la Alta Edad Media ir a la frontera significaría a menudo partir para la guerra o efectuar incursiones de saqueo (C. RILEY, "Fronteira e História Militar - Um Relance Historiográfico" in Comissão Portuguesa de História Militar, II Colóquio Sobre 
das entre dos formaciones político-religiosas antagónicas y sujetas a frecuentes incursiones musulmanas, asturianas o incluso de vikingos en las áreas costeras, las comunidades locales empezaron a establecer, para su protección y por iniciativa propia, reductos defensivos colectivos comunes a varios núcleos de poblaciones ${ }^{14}$; la dispersión demográfica y escasos recursos impedían la fortificación de todos los diminutos asentamientos. Se anunciaba así el proceso de incastellamento en la Península Ibérica, es decir, el proceso de reorganización popular del territorio rural en función de los castillos, que permitían defender a las comunidades circundantes (amasare homines, congregare populum).

Las primeras de estas estructuras ${ }^{15} \mathrm{se}$ encontraban ubicadas en la región situada a norte del río Duero, datando de mediados del siglo IX subsecuentemente al inicio de las acciones de presura emprendidas por Alfonso I de Asturias (693-757). Estas estructuras defensivas ya no eran murallas defendiendo poblados circunscritos sino estructuras específicamente militares de ámbito territorial para vigilancia y defensa (esporádica) de bienes y personas, pudiendo albergar un pequeño contingente militar durante períodos temporales. La diferencia entre el castillo roquero y el hîşn musulmán

Monumentos Militares Portugueses - Panorama e Perspectivas Actuais da História Militar em Portugal, Lisboa, 1991, pp. 290-291).

${ }^{14}$ Sobre las fortificaciones prerrománicas y románicas en el territorio portugués, ver: M. J. BARROCA, "Castelos Românicos Portugueses (Séc. XII e XIII)" in X. C. V. PÉREZ, J. RODRIGUES (coord.), Romanico: En Galicia y Portugal / Em Portugal e Galiza, A Coruña - Lisboa, 2001, pp. 89-111; M. J. BARROCA, "Do Castelo da Reconquista ao Castelo Românico (Séc. IX a XII)", Portvgalia, 11-12, Oporto, 1990, pp. 88-136; C. F. ALMEIDA, "Séculos X a XIII" in R. MOREIRA (dir.), História das Fortificações Portuguesas no Mundo, Lisboa, 1989, pp. 3854; C. F. ALMEIDA, Castelologia Medieval de Entre-Douro e Minho: Desde as Origens a 1220, Porto, Tesis Complementar del Doctorado (Universidad de Oporto), 1978.

\footnotetext{
${ }^{15}$ Varios castros prerromanos abandonados durante el imperio romano fueron reocupados en ésta época por parte de poblaciones que buscaban refugios seguros.
}

es que, mientras el último estaba integrado en un sistema defensivo armónico subordinado a un poder central, en el primero existía una vocación para la defensa individual del territorio circundante. A partir del siglo IX se asistió al establecimiento de una densa malla de fortificaciones, especialmente en la región situada en ambas márgenes del curso final del río Duero.

De acuerdo con Mário Barroca, los esfuerzos colectivos de cada comunidad produjeron una enorme diversidad de soluciones arquitectónicas para los castillos roqueros ${ }^{16}$. Estos castillos - hoy reducidos a vestigios muy exiguos - se implantaban preferentemente sobre afloramientos rocosos situados en lugares elevados donde el contexto orográfico permitiera dominar visualmente las áreas limítrofes y facultar condiciones naturales de defensa. Las estructuras edificadas, muy rudimentarias y de perímetro reducido para facilitar la defensa y aminorar las exigencias constructivas, estaban formadas por una cintura amurallada desproveída de torres y presentando un acceso único y sencillo; las murallas, generalmente curvilíneas y adaptadas a la topografía rocosa, eran de piedra irregular o sumariamente aparejada y aplicada sin recurso de argamasas ${ }^{17}$; en las cortinas amuralladas se incorporaban frecuentemente las peñas del afloramiento rocoso, $\mathrm{y}$ se efectuaba la remoción de tierra lateralmente a estas para acentuar las diferencias de cota, permitiendo optimizar los medios

\footnotetext{
${ }^{16}$ Mário Barroca menciona dos de los primeros castillos roqueros presentes en la documentación medieval portuguesa: el Mons Caballus (Serzedelo, Guimarães) y el Mons Genestaxo (Paços de Gaiolo, Marco de Canavezes) (M. J. BARROCA, Op. cit. nota 14 (2001), pp. 91-92).

${ }^{17}$ También se podrían utilizar palizadas de madera; existen también algunas referencias a motas - montes artificiales antrópicos de perfil cónico comportando generalmente un foso, una palizada de madera y una torre de madera en su topo (M. J. BARROCA, "Da Reconquista a D. Dinis" in M. T. BARATA, N. S. TEIXEIRA (dir.), Nova História Militar de Portugal, vol.1, Lisboa, 2003, p. 101).
} 
disponibles y aumentar las condiciones defensivas ${ }^{18}$.

Con Alfonso III de Asturias (c.848910) cambió significativamente el paradigma bélico: las motivaciones ya no eran de índole defensiva para la supervivencia del reino cristiano en conjunción con incursiones predatorias de saqueo buscando expolios; los cristianos eligieron como objetivo principal la expansión y control territorial con intención deliberada de tomar los territorios semiautónomos y las ciudades con parca implantación musulmana situadas en la frontera sur. Después de la toma de Portucale (Oporto) en 868 por Vimara Pérez (c.820-873) se siguió la toma del territorio de Entre-Douro-e-Minho y de Trás-osMontes en los años siguientes, permitiendo establecer la frontera en el río Duero; en la zona litoral estaría un poco más a sur, sensiblemente en el río Vouga, aunque momentáneamente se haya extendido hasta el río Mondego con la toma de Colímbria (Coimbra) en 878 por Hermenegildo Gutiérrez (c.842-920) ${ }^{19}$. Frente al súbito aumento territorial del reino, Alfonso III aplicó en las áreas fronterizas un modelo de organización territorial inspirado en el kūrah musulmán: la civitas, un amplio territorio administrado militarmente a partir de un polo ubicado o no en una ciudad tutelada por un hidalgo.

\footnotetext{
${ }^{18}$ M. J. BARROCA, Op. cit. nota 14 (1990), p. 91.

${ }^{19}$ Vimara Pérez fundó el primer condado de Portucale en los territorios entre los ríos Miño y Vouga, con la frontera naciente demarcada aproximadamente por las sierras de Peneda y Marão y el curso final del río Tâmega, aunque con difusas extensiones para oriente que abarcarían después algunas partes de Trás-os-Montes, de Alto Douro y de Beira Alta, como Flavias (Chaves), Lameco (Lamego) y Viseo (Viseu). Hermenegildo Gutiérrez fue el primer conde del condado de Conímbria, que abarcaba los territorios de Entre-Mondego-e-Douro a occidente de la sierra de Estrela y del río Côa (M. J. BARROCA, "Castelos Medievais Portugueses: Origens e Evolução (Séc. IX-XIV)” in J. A. BARRIO, J. C. PLIEGO (ed.), La Fortaleza Medieval: Realidad y Símbolo, Alicante, 1998, pp. 14-15).
}

Tal se reflejó en la arquitectura militar y su respectiva implantación, ocasionando el establecimiento de una densa malla fortificada en estos nuevos territorios - una situación de fuerte incastellamento que se prolongó hasta el siglo XII, cuyos objetivos pasaban por la defensa del territorio contra incursiones extranjeras y por el control administrativo, jurídico y fiscal. Además de la implantación en sitios elevados de gran utilidad defensiva, los castillos solían situarse en lugares estratégicos sobre las regiones más densamente pobladas y principales vías de comunicación, predominando en áreas fronterizas recién tomadas. Coexistiendo paralelamente con los castillos roqueros ${ }^{20}$ se desarrolló un nuevo tipo de fortificación: el castillo condal, una evolución en la arquitectura castrense ${ }^{21}$. El castillo prerrománico de iniciativa condal, a pesar de mantener una simplicidad formal, poseía planimetría más regular y recursos más artificiosos como la utilización del aparejo pétreo frecuentemente con bloques dentados de encaje y el surgimiento (excepcional) de la torre cuadrangular como refugio o residencia - el castillo condal podría ser incluso una torre fortificada con entrada a un nivel superior, rodeada o no por un recinto amurallado $^{22}$.

${ }^{20}$ Aunque con alteraciones posteriores, los castillos de Moreira de Rei y de Aguiar da Pena aún permiten vislumbrar cómo fueron su implantación y trazado iniciales.

${ }^{21}$ Las designaciones usuales para los castillos roqueros en los documentos medievales eran mons, monte, castrum, alpe, pena o penella, mientras que los castillos condales, considerados más importantes, poseían la designación de castellum (C. F. ALMEIDA, Op. cit., nota 14 (1978), pp. 6-8).

${ }^{22}$ Como el castillo condal de Trancoso que, aunque modificado, sigue siendo visible. Los castillos de S. Mamede (Guimarães), de Lanhoso (Póvoa de Lanhoso) y de Feira (Santa Maria da Feira) presentan vestigios del castellum originario en sus fundaciones (M. J. BARROCA, Op. cit. nota 14 (1990), pp. 94-115). 
Después de una retracción en la expansión territorial ${ }^{23}$ inducida por la reacción musulmana patente en las incursiones de Abu 'Amir Muhammad al-Ma afirí (c.938-1002), el célebre Almanzor - crisis acentuada por incursiones de vikingos que asolaron el litoral entre finales del siglo $X$ e inicios del siglo XI -, la iniciativa cristiana recibió nuevo aliento con Fernando I de León (c.1016-1065) el Magno. La unificación de los reinos cristianos de Navarra y León que se habían formado antes - y la caída del régimen califal omeya, disgregado en pequeños feudos soberanos designados como tā'ifah (taifa) ${ }^{24}$, propició una nueva oleada de expansión rápida del territorio cristiano. En el territorio actualmente portugués, Fernando Magno emprendió a mediados del siglo XI una campaña para recuperar los territorios perdidos durante las incursiones de Almanzor, culminando con la conquista definitiva de Coimbra en 1064.

Como premio por los servicios prestados en la reocupación de Coimbra, Fernando Magno concedió al mozárabe Sisnando Davidiz (†1091) el gobierno del restablecido condado de Coimbra. Sisnando inmediatamente mandó reparar y construir diversos castillos considerados fundamentales para la defensa del territorio, sobre todo los que formaban parte de la línea defensiva de Coimbra ${ }^{25}$. Según Mário Barroca, estos castillos estaban mejor construidos que los anteriores castillos, tal vez porque Sisnando había servido al gobernante de la $t \bar{a}^{\prime} i f a h$ de Sevilla como wazìr (visir, una especie de

${ }^{23}$ La línea de frontera, que se había establecido en el río Mondego durante cerca de un siglo después de la toma de Colímbria, retrocedió con la pérdida de territorios provocada por la reacción musulmana de Almanzor.

\footnotetext{
${ }^{24}$ Mientras que la defensa musulmana en el período omeya estaba constituida por un sistema integral centralizador, con el sistema de $t a a^{\prime} i f a h$ se cambió de paradigma para una estrategia individualizada basada sobre todo en la fortificación de la capital de cada $t \bar{a}$ 'ifah (R. V. GOMES, Op. cit. nota 3, p. 30).

${ }^{25}$ Por ejemplo los castillos Soure, de Penela, de Montemor-o-Velho, de Arouce (Lousã) y de Miranda do Corvo.
}

ministro), adquiriendo gran conocimiento de la arquitectura militar musulmana, más desarrollada que la cristiana ${ }^{26}$. Efectivamente, durante el período califal omeya la arquitectura defensiva musulmana sufrió innovaciones de influencia siria como la utilización de planimetrías más regulares, del acceso en recodo y de torreones cuadrangulares menos salientes y con distancias más cercanas entre sí.

Quizás directamente inspirado en el hîşn y el burdj musulmanes, los castillos protorrománicos sisnandinos presentaban diversas novedades: aunque mantuvieran en muchos casos la organicidad planimétrica adaptada a la topografía, la geometrización regularizada comenzó siendo más constante; las reducidas dimensiones amuralladas no impidieron la existencia de alcázares y cisternas en algunas de las estructuras; las torres empezaron a adquirir forma semicilíndrica, reforzando puntos más vulnerables como puertas, ángulos y cortinas amuralladas más extensas; y el aparejo pétreo era más regular acercándose de la isodomía (sillares con altura regular en cada hilera $)^{27}$.

La atribución a Sisnando del gobierno del condado de Coimbra patentaba otro aspecto importante registrado en el reinado de Fernando Magno a nivel de administración y defensa territorial: la gradual substitución de la civitas por la terra como elemento preferente para la defensa territorial, ocurriendo entre finales del siglo XI e inicios del siglo XII. Si por un lado se revelaba la inoperancia defensiva de vastas áreas coordinada a partir de la civitas, por otro el excesivo protagonismo por parte de sus gobernantes ${ }^{28}$ imponía una solución distinta de la existente. Las

\footnotetext{
${ }^{26}$ M. J. BARROCA, Op. cit. nota 14 (1990), p. 104.

${ }^{27}$ M. J. BARROCA, Op. cit. nota 14 (1990), pp. 104105.

28 Un caso ilustrativo fue el de Nuno Mendes (†1071), conde portucalense que en 1071 se insurreccionó contra su rey Garcia de Galiza (c.1040-1090); el resultado fue su derrota y muerte y el fin del primer condado de Portucale.
} 
terras eran unidades territoriales de menor dimensión capitaneadas por un solo castillo cuya defensa era atribuida por el monarca a un tenens perteneciente a los milites (clase guerrera proveniente de la aristocracia local o de los infanções, descendientes aristócratas no sucesores del respectivo título nobiliario). Mientras la defensa territorial se optimizaba mediante el tratamiento específico para cada lugar, Fernando Magno estableció simultáneamente un régimen señorial más fiel al rey que se contraponía al poder condal ${ }^{29}$. Las terras surgieron inicialmente en territorios recién-conquistados donde era más fácil implantar la nueva nobleza, como el territorio entre los ríos Duero y Mondego.

Fue este sistema el que irónicamente permitió la progresiva autonomización del condado Portucalense respecto al reino de León, empezado por sus primeros condes Enrique de Borgoña (1066-1112) y su esposa Teresa de León (1080-1130). A Enrique de Borgoña le había sido concedida en matrimonio la hija ilegítima de Alfonso VI (10391109) de Castilla y León junto con el condado Portucalense (los antiguos condados de Conímbria y de Portucale) como recompensa por sus servicios contra los musulmanes, que se habían unificado y fortalecido bajo los almorávides. La independencia de Portugal fue lograda en 1139 por su hijo Alfonso I Henríquez (c.1109-1185) el Conquistador, que se apoyó precisamente en el sistema de terras para consolidar la independencia de Portugal frente al reino leonés.

De hecho, Alfonso Henríquez trasladó en 1131 la capital a Coimbra, ubicada en el territorio predominantemente dominado por terras; apoyándose en sus tenentes, emprendió no sólo la expansión territorial

\footnotetext{
${ }^{29}$ Según Rita Costa Gomes, podría existir una probable influencia del otro lado de los Pirineos a causa de los caballeros nobles que iban a luchar por los reinos cristianos peninsulares. La tradición franca concedía el gobierno de castillos fronterizos y territorios adyacentes a caballeros nobles a cambio de su fidelidad (hominium) al rey; el juramento significaba el reconocimiento de la autoridad real (R. C. GOMES, Castelos da Raia: Trás-osMontes, Lisboa, 2003, p. 9).
}

hacía el sur sino también el fortalecimiento de su poder frente a los grandes aristócratas del norte. Es más: como forma de garantizar el dominio del Entre-Douro-e-Minho (frente a los gallegos y gran aristocracia local) y adquirir control en Trás-os-Montes y Beira Alta (frente a los leoneses) ${ }^{30}$, Alfonso Henríquez creó una proliferación de terras en esos territorios, concedidas a milites de su confianza.

Mientras consolidaba su autoridad en las tierras fronterizas septentrionales y orientales, Alfonso Henríquez prosiguió la expansión territorial hacía sur ${ }^{31}$ aprovechando la desintegración de los territorios almorávides en 1144, una vez más disgregado en $t \bar{a}^{\prime} i f a h$. Por primera vez se estableció de modo consistente el dominio en la Estremadura (entre los ríos Tajo y Mondego) con la conquista de Lisboa en 1147, sometiéndose fugazmente territorios en el Alentejo y casi alcanzando el Algarve.

Alfonso Henríquez estableció también una estrategia para la defensa, consolidación y expansión territorial apoyándose en las órdenes religiosas militares, poseedoras de la más avanzada tecnología militar adquirida con las cruzadas en la Tierra Santa. A cambio de fidelidad y auxilio a la corona portuguesa, fueron concedidos territorios a las diversas órdenes, que tendrían que defenderlas y desarrollarlas ${ }^{32}$.

${ }^{30}$ Rita Costa Gomes afirma que, para impedir la influencia leonesa sobre Trás-os-Montes, Alfonso Henríquez atrajo hacia la esfera portuguesa el aristócrata local Fernán Méndez (1095-1160) el Braganção, concediéndole privilegios y el matrimonio con su hermana Sancha Henríquez (c.1095-1163) (R. C. GOMES, Op. cit., nota 29, pp. 9-11). La política de concesión de terras se extendió a la Beira, región situada en la parte oriental de la sierra de Estrela y bajo influencia leonesa y musulmana, considerada un importante pasaje natural entre el norte y el sur (GOMES, R. C., Castelos da Raia: Beira, Lisboa, 2002, p. 4).

${ }^{31}$ Los territorios musulmanes situados a sur de cada reino eran considerados su área de expansión natural.

${ }^{32}$ La defensa sur de Coimbra, de parte del curso medio del río Tajo y de parte de la raya entre Portugal y el reino de León fue concedida a la orden del Templo 
Se estableció así una red de fortificaciones fieles a la monarquía portuguesa en las diversas terras, estratégicamente concedidas por Alfonso Henríquez en las zonas más sensibles del territorio portugués. Además de la defensa contra incursiones musulmanas, los castillos ahí existentes aseguraban la consolidación de la independencia frente a las aspiraciones integracionistas del reino de León.

La importancia de las terras ocasionó otro hecho significativo: la hegemonía impuesta por los tenentes para su castillo, rechazando potenciales rivalidades por parte de otros castillos ahí existentes, ocasionó un proceso selectivo de jerarquización que condujo al abandono de muchos castillos en finales del siglo XI. La reducción de castillos permitió concentrar esfuerzos económicos y materiales en los que eran el centro militar de la terra, viabilizando un incremento en la evolución arquitectónica defensiva ${ }^{33}$. Cambió también el paradigma bélico: conquistar un territorio ya no era conquistar su ciudad sino su castillo, que adquiriera el designio de referencia territorial e incluso vivencial. La implantación de los castillos románicos, aunque aprovecharan afloramientos rocosos y lugares elevados proporcionando condiciones propicias a la defensa y control visual del territorio (con el recurso de las atalayas), empezaron a establecerse cada vez más en asociación a los principales poblados, vías de comunicación vitales y áreas de mayor productividad, adquiriendo creciente protagonismo en inmensos aspectos de las vivencias diarias de su comunidad.

(presente en Portugal desde 1128); la orden del Hospital (presente en Portugal desde c.1126-28) tenía a su cargo parte del curso medio del río Tajo y parte del Alto Alentejo; a la orden de Avis (ramo portugués de la orden de Calatrava, presente en Portugal desde 1175) estaba confiada la parte rayana del Alto Alentejo; los dominios de la orden de Santiago da Espada (presente en Portugal desde 1172) se extendían por el margen litoral sur del Tajo y en parte de la raya del Baixo Alentejo y del Algarve.

${ }^{33}$ M. J. BARROCA, Op. cit., nota 19 (1998), pp. 21-23.
Las prerrogativas poliorcéticas del castillo románico se basaban en una estrategia defensiva de ámbito pasivo comandada a partir de un polo neurálgico robustamente fortificado que funcionaba como último reducto. La defensa se hacía mediante un sistema concéntrico de varias líneas, aumentando el nivel de fortificación de la periferia hacia el centro intentando dificultar la progresión enemiga hasta el reducto final ${ }^{34}$. El castillo románico ${ }^{35}$ trajo importantes innovaciones a la arquitectura militar: las murallas se tornaron más robustas en altura y espesura para obstaculizar la escalada y los trabajos de zapa, siendo generalmente hechas con sillares isodomos en ambos lados que después eran rellenados con gravilla, arena y pequeñas piedras compactadas y consolidadas puntualmente por perpiaños; también empezaron a surgir con más frecuencia torres y cubos (cuadrangulares en las regiones graníticas del norte, circulares en las regiones esquistosas o con materiales menos resistentes) adosados a la muralla en las partes continuas más extensas o cuando esta cambiaba de dirección, permitiendo mayor vigilancia y defensa. En el relativamente exiguo perímetro amurallado, que posibilitaba su defensa con pequeñas guarniciones, solían existir un patio, el pozo o cisterna, la oficina de fundición y un eventual edificio de acuartelamiento. Procurando evitar la multiplicación de aberturas consideradas puntos vulnerables en la defensa, los accesos se restringían a una o dos puertas (la puerta principal y la poterna, de menores dimensiones y generalmente disimulada); las saeteras empezaron a surgir en puntos específicos de las murallas y torres ${ }^{36}$.

El castillo románico portugués recibió también una notable contribución

\footnotetext{
${ }^{34}$ M. J. BARROCA, Op. cit., nota 14 (1990), p. 106.

${ }^{35}$ Algunos ejemplos de castillos románicos son los de S. Mamede (Guimarães), de Belver, de Sortelha, de Marialva o de Castelo Mendo.
}

${ }^{36}$ M. J. BARROCA, Op. cit., nota 15 (2001), pp. 102108. 
concedida por las órdenes religiosas militares $^{37}$, en especial por los templarios que poseían los más avanzados conocimientos de poliorcética adquiridos en el Próximo Oriente. Se comprende porque fueran encargados de defender zonas cruciales del reino; bajo el impulso de Gualdim Pais ${ }^{38}$ (1118-1195), gran maestre de los templarios portugueses regresado de la Tierra Santa en 1156, estos iniciaron una intensa campaña de obras construyendo o remodelando sus castillos $^{39}$. Entre las diversas innovaciones aportadas por ellos al panorama castrense portugués se incluyen la torre del homenaje $\mathrm{e}^{40}$, quizás la mayor innovación románica; también introdujeron el cadahalso, el alambor, el antepecho doble, la antepuerta

${ }^{37}$ Sobre las fortificaciones de las órdenes religiosas militares en Portugal, ver: I. C. FERNANDES, L. F. OLIVEIRA, "As Ordens Militares no Reino de Portugal" in C. A. MARTÍNEZ, F. N. PORTELA (coord.), As Ordens Militares na Europa Medieval, Lisboa, 2005, pp. 137-165; M. J. BARROCA, “Os Castelos das Ordens Militares em Portugal (Sécs. XII a XIV)" in I. C. FERNANDES (coord.), Mil Anos de Fortificações na Península Ibérica e no Magreb (500-1500), Lisboa, 2002, pp. 535-548; M. J. BARROCA, Castelos da Ordem de Santiago, Palmela, 2002; M. J. BARROCA, "A Ordem do Hospital e a Arquitectura Militar Portuguesa (Séc. XII a XIV)" in V. O. JORGE (coord.), III Congresso de Arqueologia Peninsular: Arqueologia da Idade Média da Península Ibérica, vol.7, Oporto, 2001, pp. 187-211; I. C. FERNANDES, "Castelos da Ordem de Santiago: A Região do Sado" in V. O. JORGE (coord.), III Congresso de Arqueologia Peninsular: Arqueologia da Idade Média da Península Ibérica, vol.7, Oporto, 2001, pp. 169-185; M. J. BARROCA, "A Ordem do Templo e a Arquitectura Militar Portuguesa do Séc. XII", Portvgalia, 17-18, Oporto, 1996, pp. 171-209.

${ }^{38}$ Gualdim Pais participó en la Segunda Cruzada recorriendo la Tierra Santa de norte (donde combatiera al rey sirio) a sur (combatió al sultán egipcio), contactando con la arquitectura defensiva de los cruzados - la más avanzada de la época.

${ }^{39}$ Algunos castillos templarios portugueses son los de Tomar, de Almourol, de Pombal y de Longroiva.

${ }^{40}$ Se atribuye a los templarios la introducción de la torre del homenaje en Portugal porque la más antigua datación disponible está en una torre del homenaje de origen templaria; no obstante, tal no invalida alguna posible influencia a partir del donjon francés trasladado por caballeros franceses o incluso una evolución a partir de los castillos condales torreados. y el torreón de planta pentagonal, elementos adoptados con mayor o menor grado ${ }^{41}$. También los hospitalarios eran poseedores de avanzados conocimientos de poliorcéti$\mathrm{ca}$, como demostraron en sus castillos.

Igualmente importante para la definición del castillo románico fue influencia de la arquitectura militar almorávide: los almorávides introdujeron importantes innovaciones en los castillos musulmanes ${ }^{42}$, siendo la más importante el uso de la tapia militar (tierra argilosa, inertes y cal prensados en encofrados), tecnología de origen magrebina y sur-hispánica más barata y de más rápida construcción ${ }^{43}$. Las influencias más grandes fueron con respecto al trazado poligonal de las fortificaciones, donde las murallas poseían torres cuadrangulares (debido al uso de la tapia) colocadas espaciadamente y en cada inflexión de dirección, a la utilización de entradas en recodo flanqueadas por torres, de murallas coronados por almenas ${ }^{44} \mathrm{y}$ adarves aprovechando su espesura, y por el surgimiento de los albacares para proteger a la población y al ganado.

Los castillos románicos fueron la esencia de control y afirmación territorial durante la Reconquista Cristiana en Portugal, no sólo como bastiones defensivos sino también como polos dinamizadores de la población y de desarrollo administrativo y económico de los territorios conquistados. Se pueden vislumbrar distintas fronteras entre cristianos y musulmanes, perceptibles mediante la observación de redes fosilizadas de castillos implantados siguiendo 202.

${ }^{41}$ M. J. BARROCA, Op. cit., nota 37 (1996), pp. 182-

${ }^{42}$ Algunas fortificaciones almorávides importantes eran las de Cacela, de Tavira, de Alcácer do Sal, de Palmela o de Salvaterra.

${ }^{43}$ C. TORRES, S. MACIAS, Op. cit., nota 3, p. 37.

44 Las almenas del período románico adoptadas por los cristianos solían ser altas, estrechas y con perfil rectangular o pentagonal (a veces también piramidal o en arco quebrado) con dimensión semejante a la de la abierta. 
líneas estratégicas ${ }^{45}$. El rápido avance cristiano, que había llegado al Algarve a finales del siglo XIII fue rechazado por la acción de Abū Yūsuf Ya'qūb al Mansūr (1160-1199) que, conduciendo un ejército almohade, retomó los territorios situados a sur del río Tajo y restableció ahí la frontera ${ }^{46}$.

Sólo con el decaimiento de los almohades en 1212 - una vez más por disgregación en tā'ifah - la marcha conquistadora cristiana tomó un nuevo ímpetu, culminando con la conquista de Silves en 1249 por Alfonso III (1210-1279), siendo establecida la capital portuguesa en Lisboa en 1255. Terminada la Reconquista Cristiana en el territorio portugués, había que delimitar la frontera entre los reinos de Portugal y de Castilla, tarea emprendida por el rey Dionisio I (1261-1325). Después de un corto período de guerra con el poderoso reino vecino aprovechando sus debilidades, en 1297 se firmó el tratado de Alcañices que definió la frontera entre los dos países ${ }^{47}$.

La inexistencia de accidentes geográficos relevantes que pudieran auxiliar la delimitación de la frontera entre Portugal y Castilla condujo a la adopción de una peculiar política de organización territorial. Rita Gomes compara esa política con la idea de las antiguas sociedades que delimitaban sus territorios a través del ritual de colocación de signos materiales (marcos de

${ }^{45}$ Después de la línea fronteriza situada en el río Duero, se vislumbra una línea fronteriza situada en el río Mondego y otra posterior situada sobre el río Tajo.

${ }^{46}$ No obstante se mantuvieron algunas bolsas cristianas al sur del Tajo, como la ciudad de Évora.

${ }^{47}$ Según el tratado, Portugal recuperó la soberanía sobre parte de los territorios conquistados a los musulmanes en el margen izquierdo del río Guadiana que Castilla usurpara, recibió los territorios de Riba Côa (margen derecho del río Côa) recientemente conquistados a Castilla y algunos otros en las cercanías de Badajoz; a cambio, Portugal desistió de la soberanía sobre los territorios alrededor de Aroche y Aracena y cedió los territorios a sur de Alcántara [H. B. MORENO, "As Relações de Fronteira no Século de Alcañices (1250-1350): O Tratado de Alcañices", Revista História, vol.15, Oporto, 1998, p. 646]. piedra, estacas de hierro, etc.) en sus límites: el rey Dionisio I empleó una política de fortificación de la raya donde los castillos se tornaron gigantescos marcos delimitadores del territorio. La concepción de frontera no era una línea virtual sino una sucesión de puntos funcionando como elementos de identificación. Quien poseyera el castillo poseía también las tierras y comunidades circundantes, y por eso el monarca atribuyó la administración de los castillos fronterizos como contrapartida al tributo de homenaje a su autoridad real ${ }^{48}$. Los castillos desarrollaron así un papel fundamental en la definición del territorio portugués y defensa de su integridad e independencia.

En su estrategia de consolidación, Dionisio I ignoró los castillos situados en el interior de Portugal que habían perdido su valor estratégico-militar, mientras concentró sus esfuerzos en una imponente campaña de obras de modernización y reformulación de los que protegían puntos neurálgicos: en las zonas fronterizas sin accidentes geográficos y más vulnerables, en los ejes de penetración hacia la capital Lisboa, y en las vías de comunicación vitales. La táctica urdida dio lugar a un sistema defensivo casi continuo basado en dos o tres líneas paralelas de detención periférica distribuidas a lo largo de la frontera, completadas por líneas de defensa en profundidad que acompañaban a las principales vías de comunicación, $\mathrm{y}$ formando alrededor de Lisboa una red defensiva concéntrica ${ }^{49}$.

La campaña de obras fomentada por Dionisio I permite afirmar que el monarca fue el gran promotor del gótico en la arquitectura militar portuguesa ${ }^{50}$, aunque las in-

${ }^{48}$ R. C. GOMES, "A Construção das Fronteiras", in F. BETHENCOURT, D. R. CURTO (org.), A Memória da Nação, Lisboa, 1991, pp. 370-380.

${ }^{49}$ J. G. MONTEIRO, Os Castelos Portugueses dos Finais da Idade Média: Presença, Perfil, Conservação, Vigilância e Comando, Lisboa, 1999, pp. 21-32.

50 Sobre las fortificaciones góticas en el territorio portugués, ver: J. G. MONTEIRO, Op. cit. nota 49, 1999; M. J. BARROCA, "D. Dinis e a Arquitectura Militar Por- 
novaciones góticas - que coinciden con el cambio de la defensa pasiva a la defensa activa de contraataque a partir de las posiciones defensivas - ya estaban presentes en el territorio portugués desde la época almohade. Fruto de la intensa presión bélica de los cristianos, los musulmanes siguieron desarrollando las tecnologías defensivas, logrando un elevado grado de evolución en la época almohade. Según Helena Catarino, las fortificaciones almohades ${ }^{51}$ se caracterizaban por plantas poligonales irregulares con numerosas torres adosadas a las murallas, especialmente en sus inflexiones de dirección. El elevado número de torres, complementado por la introducción de las torres albarranas, posibilitaba un eficaz flanqueo de tiro protegiendo las murallas a partir de varios ángulos distintos; los almohades introdujeron también las torres octogonales, más resistentes a los trabajos de zapa y artillería; y el empleo de corachas, que partiendo de las murallas permitía el acceso protegido a locales de valor estratégico $^{52}$.

La conquista de los territorios almohades por Alfonso III permitió un estrecho contacto con las soluciones arquitectónicas defensivas musulmanas, incorporadas después en la arquitectura defensiva portuguesa. Las innovaciones góticas provinieron también de Francia: debido al matrimonio con Matilde de Dammartín (1202-1259), Alfonso III permaneció casi veinte años en Francia como duque de Boulogne-sur-Mer, contactando con la avanzada arquitectura militar promovida el rey francés Felipe II Augusto (1165-1223) ${ }^{53}$. Así se comprende la

tuguesa", História, serie 2, vol.15, t.1, Oporto, 1998, pp. 801-822; J. V. SILVA, "Séculos XIV e XV" in R. MOREIRA (dir.), História das Fortificações Portuguesas no Mundo, Lisboa, 1989, pp. 55-71.

51 Algunas fortificaciones con importantes contribuciones almohadas son las de Silves, de Mértola, de Loulé o de Paderne.

${ }^{52}$ H. G. CATARINO, Op. cit., nota 3, pp. 628-636.

${ }^{53}$ Después de volver de la Tercera Cruzada, Felipe Augusto emprendió la reforma de los castillos reales introducción del balcón con matacanes por parte de Alfonso III en la arquitectura defensiva portuguesa.

Pero fue bajo el reinado de su hijo Dionisio I cuando apareció la gran implementación de la defensa activa en los castillos portugueses ${ }^{54}$, absorbiendo innovaciones de influencia musulmana y francesa. Dionisio I incrementó el empleo de balcones con matacanes e incluso de galerías con matacanes, evoluciones naturales del cadahalso como estructura de tiro vertical pero ahora hecha de piedra, más resistente a los proyectiles y a los daños causados por el tiempo. En una primera fase esos balcones se concentraban sobre las puertas de acceso a las torres del homenaje, pero luego se multiplicaron por otros puntos vulnerables de las fortificaciones.

La implantación de las torres del homenaje fue reconsiderada, trasladando frecuentemente su posición hacia puntos sensibles en las murallas, así tornando más eficaz su defensa. Surgieron también las torres del homenaje con planta poligonal (permitían mayor variedad de líneas de tiro), las escaraguaitas en sus ángulos superiores, y hubo una substitución de los tejados de madera y teja o colmo (vulnerables a los proyectiles incendiarios) por coberturas planas de piedra (posibilitadas por la utilización de bóvedas). Las puertas de las fortificaciones - algunas reformadas para formatos en recodo - fueron fortalecidas con torres, buheras y balcones con matacanes, y las murallas se reforzaron con la multiplicación de diversos tipos de torres (torres albarranas, torres caballeras y bestorres parciales) y con adarves más anchos y con escaleras adosadas (al revés de incorporadas en la anchura o con piedras salientes). Las almenas se tornaron más anchas - algunas con saeteras

adaptándolos a la defensa activa, inspirándose en las fortificaciones observadas en la Tierra Santa.

${ }^{54}$ Se pueden mencionar como castillos góticos los de Sabugal, de Amieira, de Vilar Maior, de Óbidos, de Beja o de Monsaraz. 
- y con abiertas más estrechas, a veces con manteletes basculantes ${ }^{55}$.

En los castillos urbanos se mantuvo la práctica de preservar la devesa (dehesa), un área libre de edificaciones en su rededor para posibilitar mejor defensa, y en algunos casos se construyeron corachas. La política de Dionisio I englobaba no sólo la construcción o remodelación de fortificaciones en puntos estratégicos sino también su poblamiento - estrategia empezada por sus antecesores -, consolidando la autoridad regia a través de su administración, dinamizando la economía local y retirando provechos fiscales ${ }^{56}$. Rita Costa Gomes menciona que "fazer vila" (hacer villa) en los tiempos medievales significaba la demarcación espacial entre las áreas urbana y rural mediante la construcción de murallas, delimitando el espacio urbano sujetado a diferentes dinámicas $^{57}$. Se puede vislumbrar una influencia francesa en la fundación de póvoas (pueblas) en regiones de la raya ${ }^{58}$, poseyendo evidentes afinidades con las bastides francesas implantadas en los territorios más lindantes ${ }^{59}$. La fundación de pueblas y el incremento de la concesión de cartas forales a comunidades convertidas en municipios sirvieron a los intentos de centralización del poder real: los municipios, sirviendo directamente al rey, se tornaban aliados regios y obstaban al poder feudal.

Si en un primer momento la institución de las terras sirvió a las tentativas regias de aminorar el poder de la gran aristocracia, en poco tiempo se convirtió en un problema, con los tenentes exigiendo cada

${ }^{55}$ M. J. BARROCA, Op. cit., nota 50, pp. 812-817.

${ }^{56}$ La importancia económica también se puede vislumbrar por ejemplo en los puentes de Ucanha (Tarouca), de Aramenha (Marvão) y de Sequeiros (Sabugal), que poseían torres fortificadas para cobrar peajes.

${ }^{57}$ R. C. GOMES, Op. cit., nota 29, p. 62.

${ }^{58}$ Algunas fundaciones urbanas nuevas son las poblaciones de Montalegre, de Vinhais, de Vila Viçosa o de Vila Nova de Cerveira.

${ }^{59}$ W. ROSSA, Op. cit., nota 7, pp. 229-234. vez más poder militar, judicial y fiscal, más territorios e incluso un ascenso social ${ }^{60}$. Los castillos donde estaban establecidos los tenentes se situaban a menudo en lugares inhóspitos defensivamente favorables; estos empezaron desde el siglo XII a trasladarse paulatinamente para sus dominios situados en lugares más agradables y accesibles, manteniendo en los castillos guarniciones militares. La construcción de domus fortis (casas-fuertes) ${ }^{61}$ por parte de nobles de menor condición se realizó frecuentemente de modo abusivo, usurpando heredades y procurando ascender socialmente con la constitución de honras (posesiones de la gran aristocracia) $)^{62}$.

De acuerdo con Mário Barroca, el segundo monarca portugués Sancho I (11541211) procedió a algunas acciones de destrucción de domus fortis que no poseerían autorización regia, intentando controlar su proliferación y respectivas consecuencias. Su hijo Alfonso II (1185-1223) prosiguió la política centralizadora del poder, visible en el rechazo a conceder a sus hermanas los

60 También el clero poseía estructuras fortificadas asociadas a sus templos, como las torres en la catedral de Lamego y en los monasterios de Salvador en Travanca, de Sta. Maria en Abade de Neiva (Barcelos), de S. Martinho en Manhente (Barcelos) o de Sta. Maria en Leça do Balio (Matosinhos). La fisonomía del edificio asumió en algunos casos una configuración fortificada, como las catedrales de Coimbra y Lisboa, la ermita templaria de Sta. Catarina en Monsaraz, la iglesia hospitalaria de Vera Cruz en Marmelar (Portel) o la capilla de N. Sra. da Assunção da Boa Nova en Terena (Alandroal) perteneciente a la órden de Avis.

${ }^{61}$ Sobre las residencias aristocráticas en Portugal, ver: J. V. SILVA, Paços Medievais Portugueses, Lisboa, 2002; R. C. GOMES, “Monarquia e Território: Residências Reais Portuguesas, Séculos XIV a XVI" in R. C. GOMES, G. SABATIER (coord.), Lugares de Poder: Europa Séculos XV a XX, Lisboa, 1998; M. J. BARROCA, “Torres, Casas-Torres ou Casas-Fortes: A Concepção do Espaço de Habitação da Pequena e Média Nobreza na Baixa Idade Média (Sécs. XII-XV)", Revista de História das Ideais, vol.19, Coimbra, 1997-1998, pp. 39-103; C. AZEVEDO, Solares Portugueses, Lisboa, 1988.

${ }^{62}$ J. G. MATTOSO, Identificação de um País: Ensaio sobre as Origens de Portugal (1096-1325), vol.1, Lisboa, 1995, p. 95. 
castillos que habían heredado. El reinado de Sancho II (1207-1248) estuvo marcado por una situación anárquica donde la aristocracia aprovechó la coyuntura de debilidad real para expandir irregularmente sus posesiones, y sólo con la subida al trono de su hermano Alfonso III, después de una guerra civil, la situación quedó controlada mediante la recuperación de las posesiones reales y el derrumbamiento de domus fortis indebidamente edificadas ${ }^{63}$.

La acción desarrollada por Dionisio I permitió consolidar el poder regio frente a la aristocracia, aboliendo el sistema de terras en pro de los julgados (de carácter más civil). Se extinguió el cargo de tenens para substituirlo por los alcaides (alcaldes) ${ }^{64}$, funcionarios de nombramiento real provenientes de la baja aristocracia que obligatoriamente prestaban homenaje al monarca y aceptaban ser fiscalizados. Dionisio I promovió igualmente un intercambio sistemático de fortificaciones fronterizas que estaban bajo dominio privado, cediendo propiedades sin interés estratégico como sucedió con su hermano el infante Pedro de Portugal (1263-1312). Se proporcionaron las condiciones para la institución del principio jurídico de ius crenelandi, el derecho al "crenelado" (siendo "crenelado" la referencia al coronamiento con almenas) y el fomento del monopolio regio para la construcción de fortificaciones, que se prolongaría hasta el reinado de Duarte I (1391-1438).

El ius crenelandi se reflejó en un apretado control sobre la edificación de residencias fortificadas; sólo en algunos casos particulares fue autorizada la edificación de casas-fuertes ${ }^{65}$. Mientras que en muchos países europeos los aristócratas generalmente podían poseer fortificaciones, en Portugal los castillos eran dominio real y su administración se efectuaba por alcal-

${ }^{63}$ M. J. BARROCA, Op. cit., nota 61, pp. 45-85.

${ }^{64}$ La jurisdicción bajo administración de los alcaides se designó como alcaidaria.

${ }^{65}$ M. J. BARROCA, Op. cit. nota 50, pp. 804-807. des nombrados por el rey. Los alcaldes no podían realizar obras de ámbito residencial privado en esas estructuras, que mantuvieron generalmente el perfil militar.

En Portugal las casas-fuertes siguieron la forma torreada a partir de la segunda mitad del siglo XII, adoptando configuraciones inspiradas en las torres del homenaje de los castillos $^{66}$. Las torres señoriales se implantaban predominantemente en locales accesibles sin preocupaciones defensivas. Mário Barroca refiere que en la Edad Media no era la forma torreada que confería el aspecto fortificado a las edificaciones, sino la existencia de almenas coronando los edificios; eso motivó la asociación de una enorme carga simbólica a las almenas, consideradas sinónimo de distinción nobiliaria. Las exiguas dimensiones y condiciones de habitabilidad de las torres evolucionaron progresivamente para el surgimiento de anexos residenciales adosados a las torres ${ }^{67}$.

La política de atribución de cartas de foral como forma de centralizar la autoridad regia y organizar el territorio, restringiendo simultáneamente los poderes aristocráticos y concediendo privilegios a los municipios, siguió siendo utilizada por los sucesores de Dionisio I. Para evitar la desertificación demográfica patente en regiones estratégicas, entre los siglos XIV y XV se implantó el recurso a los coutos de homiziados ${ }^{68}$, poblaciones situadas en la raya donde los criminales comunes podrían vivir libres sin cumplir pena efectiva. Se intentó impedir así el abandono de las fortificaciones allí situadas con la permanencia por un perío-

${ }^{66}$ Algunas domus fortis (de varias épocas) son las torres de Refóios (Ponte de Lima), de Dornelas (Amares), de Oriz en Santa Marinha (Vila Verde), de Vasconcelos en Ferreiros (Amares) y las torres más tardías de Giela (Arcos de Valdevez) o de Quintela en Vila Marim (Vila Real).

${ }^{67}$ M. J. BARROCA, Op. cit., nota 61, pp. 57-72.

${ }^{68}$ Noudar, Marvão, Arronches, Castelo Mendo, Juromenha, Caminha o Monsaraz son algunos coutos de homiziados. 
do de tiempo preestablecido de criminales condenados.

La mayor importancia de las ciudades en el contexto nacional motivó un cambio significativo en los paradigmas bélicos a partir del siglo XIV, dado que el control de un territorio ya no pasaba por el control de su castillo sino por la conquista de su ciudad principal. La preocupación por la fortificación de las ciudades fue visible principalmente durante los reinados de Fernando I (1345-1383) y de Juan I (1358-1433) de Avis - el primero a causa de las guerras contra los Trastámara por el trono de Castilla, el segundo por las guerras contra Juan I de Castilla por la sucesión de la corona portuguesa entre 1383 y 1385. En ambas situaciones el reino portugués fue invadido por tropas castellanas, motivando un imponente esfuerzo de reparación o construcción de cercas amuralladas urbanas, muchas rodeando los arrabales ${ }^{69}$. En este período surgieron las barbacanas ${ }^{70}$ - extensas o de puerta - y las lizas, así como fosos en algunas fortificaciones. Pero la importancia de las cercas amuralladas no era exclusivamente militar: las discontinuidades que introdujeron en el tejido urbano imprimieran un fuerte contraste social entre quien vivía dentro y quien vivía fuera del recinto amurallado, existiendo en algunos casos la imposición de peajes para entrar. El patrocinio de una cerca amurallada por parte del soberano demostraba la autoridad real y significaba el aprecio regio por la ciudad ${ }^{71}$.

El período subsiguiente a la crisis de la independencia portuguesa fue de relativa paz y estabilidad con el poderoso país vecino, sólo interrumpido brevemente por las aspiraciones del rey portugués Alfonso V (1432-1481) en la Guerra de Sucesión

${ }^{69}$ Por ejemplo las cercas amuralladas de Beja, de Oporto, de Lisboa, de Óbidos y de Évora, construidas o reforzadas en este período.

${ }^{70}$ La primera referencia a una barbacana fue en las fortificaciones hospitalarias de Crato y de Amieira.

${ }^{71}$ A. A. ANDRADE, Horizontes Urbanos Medievais, Lisboa, 2003, pp. 14-17.
Castellana entre 1475 y 1479. Los intereses portugueses estaban focalizados en la construcción del futuro imperio ultramarino, cuya expansión se inició en 1415 con la conquista de Ceuta (Marruecos) y que en breve se extendería de América del Sur hasta el Extremo Oriente. En los territorios ultramarinos portugueses se dieron más evoluciones en la poliorcética portuguesa, adaptada progresivamente a las nuevas exigencias y condicionalismos impuestos por el advenimiento de las armas de fuego.

El período comprendido entre mediados del siglo XV y mediados del siglo XVI fue una época de transición en Portugal a varios niveles, coincidiendo parcialmente con el reinado de Manuel I (1469-1521). El panorama arquitectónico portugués transitorio entre la Edad Media y la Edad Moderna fue dominado por el estilo manuelino: a pesar de la innovación patentada, coexistían elementos tardomedievales con elementos protorrenacentistas durante un período temporal aproximado entre los reinados de Juan II (1455-1495) y de Juan III (1502-1557). La arquitectura militar de esta época, situada en un limbo experimental entre la neurobalística y la pirobalística, es generalmente compuesta por "fortificaciones de transición"72.

Aunque la pirobalística estuviera presente en Portugal desde mediados del siglo XIV, sólo un siglo después se le empezó a conceder importancia en la arquitectura defensiva ${ }^{73}$. Mientras que en los terri-

72 En las fortificaciones de transición existió una persistencia de elementos medievalizantes hasta un período tardío. Conforme afirma Pedro Dias, en la época manuelina se manifestó una cierta continuidad en la tradición constructiva de fortificaciones; la penetración de los principios abaluartados fue inicialmente lenta aunque con experimentaciones en el dominio de la pirobalística (P. DIAS, Arquitectura Manuelina, Oporto, 1988, p. 236).

${ }^{73}$ Sobre las fortificaciones de transición portuguesas, ver: J. CORREIA, Implantação da Cidade Portuguesa no Norte de África: Da Tomada de Ceuta a Meados do Século XVI, Oporto, 2008; A. TEIXEIRA, Fortalezas - Estado Português da Índia: Arquitectura Militar na Construção do 
torios marroquíes bajo dominio portugués se construían fortificaciones que intentaban responder a los condicionalismos de la pirobalística, en Portugal Juan II decidió (aún de forma incipiente) proceder a la renovación de las fortificaciones medievales, proveyéndolas de armas de fuego e intentando también centralizar el poder regio recurriendo a la permuta de fortificaciones aristocráticas situadas en puntos estratégicos.

Fue en el reinado de su sucesor Manuel I que se concretizó una acción más sistemática de modernización de las fortificaciones fronterizas portuguesas, adaptándolas a la pirobalística dentro de un concepto más global de defensa del reino. Durante la época de transición de la neurobalística a la pirobalística se realizaron diversas intervenciones en las fortificaciones existentes, como el abajamiento y engrosamiento de las murallas existentes, la sistemática substitución de las torres cuadrangulares de tradición medieval por torreones circulares, la proliferación de cubos cilíndricos en las barbacanas, la incorporación de bastiones (cubetes artilleros) cilíndricos avanzados y adaptados a la pirobalística - algunos con casamatas - para permitir el tiro flanqueado, la introducción de troneras, y, en algunos casos, la inclusión de almenas de ladrillos preanunciando el advenimiento de los merlones ${ }^{74}$. Se construyeron también algunas cercas amuralladas con formato de "diente de sierra" cuyas protuberancias

Império de D. Manuel I, Lisboa, 2008; L. M. DUARTE, "A Marinha de Guerra; A Pólvora; O Norte de África" in M. T. BARATA, N. S. TEIXEIRA (dir.), Nova História Militar de Portugal, vol.1, Lisboa, 2003, pp. 289-441; F. F. PAULINO (coord.), A Arquitectura Militar na Expansão Portuguesa, Lisboa, 1994; R. MOREIRA, “A Época Manuelina" in R. MOREIRA (dir.), História das Fortificações Portuguesas no Mundo, Lisboa, 1989, pp. 91-142; P. DIAS, Op. cit., nota 72 .

${ }^{74}$ Algunos ejemplos de fortificaciones que sufrieron la inclusión de elementos adaptados a la pirobalística son las de Penha Garcia, de Almeida, de Torres Vedras, de Monsaraz, de Elvas, de Montalegre y de Bragança. permitían resguardar el tramo de muralla adyacente al permitir el flanqueo de tiro ${ }^{75}$.

Las experiencias poliorcéticas se fueron sucediendo durante los siglos $\mathrm{XV}$ y XVI en Portugal y su imperio ultramarino, fruto de las inmensas experimentaciones propias y de la influencia italiana recibida a través de la tratadística, de los ingenieros militares extranjeros reclutados, y de becarios portugueses que estudiaron en el extranjero. Las nuevas fortificaciones del período de transición adoptaban preferentemente dos formas: las fortificaciones de planta cuadrangular o pentagonal con bastiones en los ángulos y con una torre más alta ${ }^{76}$, y las torres defensivas generalmente adosadas a un protobaluarte ${ }^{77}$; las torres eran reminiscencias medievales que aludían a las torres del homenaje ${ }^{78}$. Ambos tipos fueron edificados en Portugal y en sus territorios ultramarinos hasta la imposición definitiva de la fortificación abaluartada a partir de la construcción de la fortaleza de Mazagán (El-Yadida) entre 1541 y 1542.

De ahí en delante no se hablaría más de "castillo" sino de "fortaleza"; se entró definitivamente en el dominio de la pirobalística donde las fortificaciones adquirieron forma abaluartada con fisonomía muy geo-

${ }^{75}$ Por ejemplo las murallas de Sagres y de Évora.

${ }^{76}$ En Portugal se pueden mencionar los castillos artilleros de Vila Viçosa, de Castro Marim, de Alfaiates (Sabugal) o el castillo Novo en Évora; en los territorios ultramarinos portugueses se pueden referir las fortificaciones de Aguz (Marruecos), de Sofala (Mozambique), de Calicut (India) o las primitivas fortificaciones manuelinas de Mazagán (Marruecos), de Ormuz (Irán) o de Chaúl (India).

${ }^{77}$ Por ejemplo la torre de S. Vicente en Belém (Lisboa), la roqueta manuelina de Viana do Castelo, la torre de Cascais o la torre de S. Sebastião en Caparica (Almada).

${ }^{78}$ En los territorios ultramarinos portugueses se levantaron diversas fortificaciones con torres tardomedievales, como en Arcila (Marruecos), Cananor (India) o Malaca (Malasia); también se construyeron otros elementos defensivos medievalizantes como las corachas de Tánger y Arcila (Marruecos) o del morro de Chaúl (India). 
metrizada para optimización del tiro flanqueante. También el léxico de la poliorcética cambió bruscamente (tecnologías, vocabulario, estrategias bélicas, vivencias militares). Las nuevas fortificaciones abaluartadas proliferaron desde mediados del siglo XVI en el mundo ultramarino portugués, y en Portugal durante la monarquía dual y sobre todo después de la Guerra de Restauración de la Independencia en 1640, cuando el país logró la emancipación de España ${ }^{79}$.

Las fortificaciones medievales que mantenían valor estratégico fueron remodeladas y modernizadas según sus posibilidades, siendo frecuentemente integradas en estructuras defensivas nuevas de mayor dimensión ${ }^{80}$. Las restantes estructuras defensivas sin importancia significativa fueron abandonadas por su obsolescencia, fueron destruidas porque se consideró que obstaban al progreso y para aprovechar sus materiales, o fueron readaptadas para otras funciones (residencias aristocráticas, prisiones, servicios públicos, almacenes, etc.), frecuentemente con graves repercusiones por desvirtuar su morfología.

José Custódio Silva afirma que el fuerte simbolismo y prestigio asociados a los alcázares musulmanes había causado en los reyes portugueses la costumbre de adoptar como residencias regias privilegiadas las que estaban asociadas a castillos ${ }^{81}$, reafirmando así su poder ${ }^{82}$. La centraliza-

${ }^{79}$ Por ejemplo las fortificaciones abaluartadas de Peniche, de S. Filipe en Setúbal, de S. Sebastião en Angra do Heroísmo (Azores), de S. Filipe en Ribeira Grande (Cabo Verde), de Taná (India), de Colonia de Sacramento (Uruguay) o de Reis Magos (Brasil).

${ }^{80}$ En Portugal se pueden mencionar las fortificaciones de Valença, de Almeida, de Elvas o de Estremoz; en los territorios ultramarinos portugueses son representativas las fortificaciones de Mazagán (Marruecos), de S. Tomé en Diu (India), de S. Sebastião (isla de Mozambique) o de Ormuz (Irán).

${ }^{81}$ Los alcázares de los castillos de Montemor-o-Velho, de Óbidos, de Lamego, de Alenquer, de Estremoz, de Coimbra o de Lisboa fueron algunas residencias reales.

${ }^{82}$ J. V. SILVA, Op. cit., nota 61, p. 25. ción del poder real y el ocaso de las casas aristocráticas más antiguas por cambio con nuevas casas feudales (en consecuencia de la coyuntura política provocada por la crisis independentista de 1383-85) proporcionó condiciones para la construcción de nuevos paços (palacios nobiliarios) reales $\mathrm{y}$ aristocráticos. Es significativo que los nuevos palacios señoriales más imponentes - algunos con características fortificadas $^{83}$ - fueron promovidos por personajes relacionados con el monarca: la real Casa de Avis y la poderosa Casa de Bragança $a^{84}$. Las alcaidarias como fuente de ingresos para sus alcaldes también permitió la reformulación o construcción de algunos alcázares situados dentro de los castillos bajo autorización regia ${ }^{85}$; en algunos casos muy esporádicos se permitió la edificación de palacios fortificados ${ }^{86}$.

${ }^{83} \mathrm{El}$ palacio regio de Leiria fue mandado construir por el Juan I dentro del castillo, denotando afinidades con la arquitectura civil palatina; el palacio de Duques de Bragança en Guimarães, iniciado en c.1420, presenta similitudes con algunos edificios nobles franceses fortificados (el primer duque de Braganza, promotor de la construcción, estuvo en ese país como diplomático); el palacio de Duques de Bragança en Barcelos, construido por el segundo duque de Bragança, poseía configuración acastillada debido al simbolismo y porque no existía castillo en la ciudad; el palacio acastillado de Ourém, situado junto al antiguo castillo, fue iniciado en c.1440 por un hijo del primer duque de Bragança después de regresar de Italia como diplomático (el edificio poseía afinidades con algunas rocas italianas); el mismo promotor erigió el palacio acastillado de Porto de Mós sobre el antiguo castillo, poseyendo una forma mixta de fortificación y de palacio civil; el palacio acastillado de Évoramonte fue edificado por el cuarto duque de Bragança, substituyendo en parte la antigua torre del homenaje destruida por un terremoto en 1531.

${ }^{84}$ La Casa de Bragança fue fundada a través del matrimonio de un hijo de Juan I con la hija del condestable Nuno Álvares Pereira (1360-1431), uno de los principales responsables por la manutención de la independencia portuguesa.

${ }^{85}$ Por ejemplo en los castillos de Valhelhas, de Longroiva, de Belmonte y de Idanha-a-Nova.

${ }^{86}$ Por ejemplo los palacios acastillados de Alvito, de Feira (Santa Maria da Feira) o de Penedono, éstos últimos edificados sobre los primitivos castillos roqueros. 
El desarrollo proporcionado por las armas de fuego condujo a la inoperancia de las almenas, progresivamente substituidas por los gigantescos merlones adaptados a la pirobalística. Sin valor defensivo, restaba a las almenas el valor simbólico íntimamente relacionado con la distinción nobiliaria, incrementada mediante el ius crenelandi; como tal, su utilización empezó liberalizándose desde principios del siglo $\mathrm{XV}$, primero en las residencias de la alta aristocracia, después en la hidalguía secundaria y finalmente entre los personajes acomodados sin título nobiliario. Debido a su fuerte carga simbólica, las casas-fuertes medievales supervivientes empezaron a ser conservadas, recuperadas e integradas en complejos residenciales solariegos, que se añadieron a las torres (cuando no existían se construían de nuevo, algunas copiando modelos antiguos) ${ }^{87}$. La utilización (a veces heteróclita) de almenas les concedía el aspecto señorial, siendo utilizadas incluso en el período barroco sobre todo en los solares del norte del país.

\footnotetext{
${ }^{87}$ Ejemplos de reutilización y ampliación de torres señoriales para edificios residenciales a partir del siglo XV: los palacios de Giela (Arcos de Valdevez), de Barbosa (Penafiel), de Ribafria (Sintra) o de Vasconcelos en Santiago da Guarda (Ansião). Ejemplos de construcción de nuevas torres en edificios señoriales: los palacios de Pinheiros (Barcelos), de Águias en Brotas (Mora) o de Carvalhal (Montemor-o-Novo) (J. V. SILVA, Op. cit., nota 61, pp. 168-180).
} 